\title{
Lambl's Excrescences in Congenital Heart Disease and Other Clinical Situations: A Series of 17 Cases
}

\author{
John Jairo Araujo ${ }^{1 *}$ and Tareq Rahimy ${ }^{2}$ \\ ${ }^{1}$ Vall d'Hebron University Hospital, Barcelona, Catalonia, Spain; Department of Clinic and Research Cardiology, \\ Meintegral Clinic, Colombia; ${ }^{2}$ University of zagreb school of medicine; Pilgrim Hospital, UK
}

\begin{abstract}
Lambl's excrescences have a low prevalence in the general population. Although they occur most frequently in adults over 60 years-old, pediatric cases have been described. The cases in adulthood are associated with ischemic stroke, but in childhood they are asymptomatic. The aim of reporting on this case series is to show the association or coexistence of Lambl's excrescences with some congenital heart diseases (CHDs), of which there are no known descriptive case series in adults or children. We present 17 patients (8 females), with a mean age of 23.7 years; among these cases, $64.7 \%$ were under 18 years-old. We found that $94 \%$ of the Lambl's excrescences were located on the aortic valve. In $47 \%$ (8 cases), they coincided with a CHD (with 6 of those individuals being under 18 years-old). We propose the hypothesis that Lambl's excrescences could have a congenital origin or coexist with CHD. No complications were found throughout the follow-up. Lambl's excrescences could be more frequent than currently reported in the literature, and more research should be done on their significance in CHD-associated stroke.
\end{abstract}

\section{Introduction}

Lambl's excrescences (LEx), also referred to as valvular strands, are thin, filiform and hypermobile processes first described on the aortic valve (AV) by Bohemian physician Vilem Dusan Lambl in 1856. ${ }^{1}$ They begin as small thrombi on the coaptation points of the endocardial surfaces and have the potential to embolize to distant organs and cause stroke or myocardial infarction. These strands are almost exclusively seen on the left side of the heart at the valve closure site, where there is endothelial damage due to wear and tear. However, they can occur anywhere on the semilunar valves and they are found in natural or prosthetic valves. ${ }^{2,3}$

LEx are most frequent in adults over 60 years-old, but pediatric cases have also been described. Phillips et al. ${ }^{4}$ reported a low prevalence of only $1.7 \%$ in 700 pediatric patients assessed with tran-

Keywords: Lambl's excrescences; Congenital heart disease; Stroke.

Abbreviations: CHD, congenital heart disease; CHDs, congenital heart diseases; LEx, Lambl's excrescences; AV, aortic valve; AVs, aortic valves; TTE, transthoracic echocardiography; TTEs, transthoracic echocardiograms; TEE, transesophageal echocardiogram; TEEs, transesophageal echocardiograms; MV, mitral valve; VSD, ventricular septal defect.

Received: October 07, 2018; Revised: December 12, 2018; Accepted: December 13, 2018

*Correspondence to: John Jairo Araujo, Department of Clinic and Research Cardiology. Meintegral Clinic, Colombia, Postal code: 0956. Tel: +5768740201;

E-mail: johnjairoaraujo@gmail.com

How to cite this article: Araujo JJ, Rahimy T. Lambl's Excrescences in Congenital Heart Disease and Other Clinical Situations: A Series of 17 Cases. Exploratory Research and Hypothesis in Medicine 2018;3(4):79-83. doi: 10.14218/ERHM.2018. 00016 . sthoracic echocardiography (TTE). In general, they are benign and do not require intervention or more aggressive invasive imaging. LEx can occur as singular or multiple strands. They are referred to as 'giant' LEx if they form a complex that is greater than or equal to $2 \mathrm{~cm}$ in diameter; the literature associates these giant LEx with ischemic stroke, angina, and even myocardial infarction. ${ }^{5,6}$ They are also described in association with rheumatic valvulitis, aortic stenosis, and bicuspid AV. ${ }^{7}$ Differential diagnoses for LEx include myxomas, thrombi, cardiac neoplasms, vegetations and metastases. From a histologic standpoint, LEx are similar to cardiac papillary fibroelastomas. Specifically, they are composed of fibroelastic and hyalinized stroma covered by a layer of endothelial cell lining. ${ }^{8}$

Materials and methods

We present here 17 consecutive cases ( 8 females), with a mean age of 23.7 years ( $0-76$ years), who were examined by the cardiology department of a Level III hospital, and who, for various reasons (Table 1), underwent echocardiography [14 transthoracic echocardiograms (TTEs) and 3 transesophageal echocardiograms (TEEs), all performed by the same expert examiner]. A multifrequency transducer $(3-7 \mathrm{MHz})$ was used in a parasternal long axis echocardiographic view of the left ventricle, focusing the study on the outflow tract and AV, with zoom images and second harmonic imaging for the adults. In the TEE cases, a 14-mm multiplane probe (4-7 MHz) was used in the medial transesophageal plane with a $135^{\circ}$ angulation over the left ventricular outflow tract and AV. Both studies used the same equipment, namely the Vivid S5 ultrasound 
Table 1. Demographic, anatomical and echocardiographic variables

\begin{tabular}{|c|c|c|c|c|c|c|c|c|}
\hline Case & Sex & Age & Reason & Echo & Location & Main diagnoses & Management & Follow-up outcome \\
\hline 1 & M & 14 & murmur & TTE & aortic valve & $\begin{array}{l}\text { minimal aortic } \\
\text { valve regurgitation }\end{array}$ & $\begin{array}{l}\text { echocardiographic } \\
\text { surveillance }\end{array}$ & $\begin{array}{l}\text { asymptomatic at } 12 \\
\text { month follow-up }\end{array}$ \\
\hline 2 & $\mathrm{~F}$ & 12 & syncope & TTE & aortic valve & none & $\begin{array}{l}\text { echocardiographic } \\
\text { surveillance }\end{array}$ & $\begin{array}{l}\text { asymptomatic at } 11 \\
\text { month follow-up }\end{array}$ \\
\hline 3 & $\mathrm{~F}$ & 26 & $\begin{array}{l}\text { pulmonary } \\
\text { hypertension }\end{array}$ & TTE & aortic valve & $\begin{array}{l}\text { DORV + subaortic } \\
\text { VSD + pulmonary } \\
\text { hypertension }\end{array}$ & $\begin{array}{l}\text { specific management for } \\
\text { pulmonary hypertension } \\
\text { sildenafil + bosentan, } \\
\text { echocardiographic } \\
\text { surveillance }\end{array}$ & $\begin{array}{l}\text { Eisenmenger syndrome, } \\
\text { no neurological event } \\
\text { at } 18 \text { month follow-up }\end{array}$ \\
\hline 4 & M & 32 & septic shock & TEE & aortic valve & $\begin{array}{l}\text { Non-stenotic } \\
\text { bicuspid valve }\end{array}$ & $\begin{array}{l}\text { aspirin } 100 \mathrm{mg} \text {, } \\
\text { echocardiographic } \\
\text { surveillance }\end{array}$ & $\begin{array}{l}\text { asymptomatic, no } \\
\text { neurological event at } \\
14 \text { month follow-up }\end{array}$ \\
\hline 5 & $\mathrm{~F}$ & 40 & syncope & TTE & aortic valve & $\begin{array}{l}\text { minimal aortic } \\
\text { valve regurgitation }\end{array}$ & $\begin{array}{l}\text { aspirin } 100 \mathrm{mg}, \\
\text { atorvastatin } 20 \mathrm{mg}\end{array}$ & $\begin{array}{l}\text { asymptomatic at } 13 \\
\text { month follow-up }\end{array}$ \\
\hline 6 & $\mathrm{~F}$ & 4 & $\begin{array}{l}\text { ventricular } \\
\text { septal defect }\end{array}$ & TTE & aortic valve & $\begin{array}{l}\text { restrictive } \\
\text { perimembranous } \\
\text { septal defect }\end{array}$ & $\begin{array}{l}\text { aortic regurgitation, } \\
\text { surgical repair VSD } \\
\text { echocardiographic } \\
\text { surveillance }\end{array}$ & $\begin{array}{l}\text { minimal aortic valve } \\
\text { regurgitation at } 8 \\
\text { month follow-up }\end{array}$ \\
\hline 7 & $\mathrm{~F}$ & 74 & $\begin{array}{l}\text { mitral valve } \\
\text { regurgitation }\end{array}$ & TEE & aortic valve & $\begin{array}{l}\text { moderate } \\
\text { functional mitral } \\
\text { regurgitation, } \\
\text { heart failure }\end{array}$ & $\begin{array}{l}\text { surgical valve replacement, } \\
\text { anticoagulation warfarin } \\
\text { therapy, echocardiographic } \\
\text { surveillance }\end{array}$ & $\begin{array}{l}\text { asymptomatic at } 7 \\
\text { month follow-up }\end{array}$ \\
\hline 8 & M & 9 & $\begin{array}{l}\text { history of } \\
\text { Kawasaki } \\
\text { disease }\end{array}$ & TTE & aortic valve & none & $\begin{array}{l}\text { aspirin } 3 \mathrm{mg} / \mathrm{kg} / \mathrm{day}, \\
\text { echocardiographic } \\
\text { surveillance }\end{array}$ & $\begin{array}{l}\text { asymptomatic at } 12 \\
\text { month follow-up }\end{array}$ \\
\hline 9 & $M$ & 11 & murmur & TTE & aortic valve & $\begin{array}{l}\text { minimal aortic } \\
\text { valve regurgitation }\end{array}$ & $\begin{array}{l}\text { echocardiographic } \\
\text { surveillance }\end{array}$ & $\begin{array}{l}\text { asymptomatic at } 15 \\
\text { month follow-up }\end{array}$ \\
\hline 10 & $\mathrm{~F}$ & 12 & endocarditis & TTE & $\begin{array}{l}\text { mitral } \\
\text { biologic } \\
\text { valve } \\
\text { prosthesis }\end{array}$ & $\begin{array}{l}\text { non-endocarditis } \\
\text { mitral biologic } \\
\text { valve prosthesis }\end{array}$ & $\begin{array}{l}\text { aspirin } 3 \mathrm{mg} / \mathrm{kg} / \mathrm{day} \text {, } \\
\text { echocardiographic } \\
\text { surveillance }\end{array}$ & $\begin{array}{l}\text { asymptomatic at } 12 \\
\text { month follow-up }\end{array}$ \\
\hline 11 & $M$ & 46 & leukemia & TTE & aortic valve & none & $\begin{array}{l}\text { echocardiographic } \\
\text { surveillance }\end{array}$ & $\begin{array}{l}\text { asymptomatic at } 8 \\
\text { month follow-up }\end{array}$ \\
\hline 12 & M & 0 & cyanosis & TTE & aortic valve & tetralogy of Fallot & $\begin{array}{l}\text { surgical repair at } 6 \\
\text { months of age }\end{array}$ & no data yet \\
\hline 13 & M & 15 & $\begin{array}{l}\text { bicuspid } \\
\text { aortic valve }\end{array}$ & TTE & aortic valve & $\begin{array}{l}\text { non-stenotic } \\
\text { bicuspid } \\
\text { aortic valve }\end{array}$ & $\begin{array}{l}\text { aspirin } 100 \mathrm{mg} \text {, } \\
\text { echocardiographic } \\
\text { surveillance }\end{array}$ & $\begin{array}{l}\text { asymptomatic at } 9 \\
\text { month follow-up }\end{array}$ \\
\hline 14 & $M$ & 16 & syncope & TTE & aortic valve & $\begin{array}{l}\text { bicuspid valve, } \\
\text { late repair of } \\
\text { aortic coarctation }\end{array}$ & $\begin{array}{l}\text { echocardiographic } \\
\text { surveillance }\end{array}$ & $\begin{array}{l}\text { asymptomatic at } 12 \\
\text { month follow-up }\end{array}$ \\
\hline 15 & $\mathrm{~F}$ & 8 & $\begin{array}{l}\text { Fontan } \\
\text { dysfunction } \\
\text { evaluation }\end{array}$ & TTE & aortic valve & $\begin{array}{l}\text { dilated left } \\
\text { ventricle, sinus } \\
\text { node dysfunction, } \\
\text { minimal aortic } \\
\text { valve regurgitation }\end{array}$ & $\begin{array}{l}\text { aspirin } 3 \mathrm{mg} / \mathrm{kg} / \mathrm{day} \text {, } \\
\text { echocardiographic } \\
\text { surveillance }\end{array}$ & $\begin{array}{l}\text { asymptomatic at } 11 \\
\text { month follow-up }\end{array}$ \\
\hline 16 & M & 8 & $\begin{array}{l}\text { aortic } \\
\text { coarctation }\end{array}$ & TTE & aortic valve & aotic coarctation & $\begin{array}{l}\text { aortic angioplasty, } \\
\text { echocardiographic } \\
\text { surveillance }\end{array}$ & $\begin{array}{l}\text { asymptomatic at } 9 \\
\text { month follow-up }\end{array}$ \\
\hline 17 & $\mathrm{~F}$ & 76 & $\begin{array}{l}\text { suspected } \\
\text { endocarditis }\end{array}$ & TEE & aortic valve & $\begin{array}{l}\text { minimal aortic } \\
\text { valve regurgitation }\end{array}$ & $\begin{array}{l}\text { aspirin } 81 \mathrm{mg} \text {, atorvastain } \\
20 \mathrm{mg} \text {, echocardiographic } \\
\text { surveillance }\end{array}$ & $\begin{array}{l}\text { asymptomatic, no } \\
\text { neurological event at } \\
15 \text { month follow-up }\end{array}$ \\
\hline
\end{tabular}

Age: years; (case 12: 1 month old newborn); TTE: transthoracic echocardiogram; TEE: transesophageal echocardiogram; DORV: double outlet right ventricle; VSD: ventricular septal defect. 


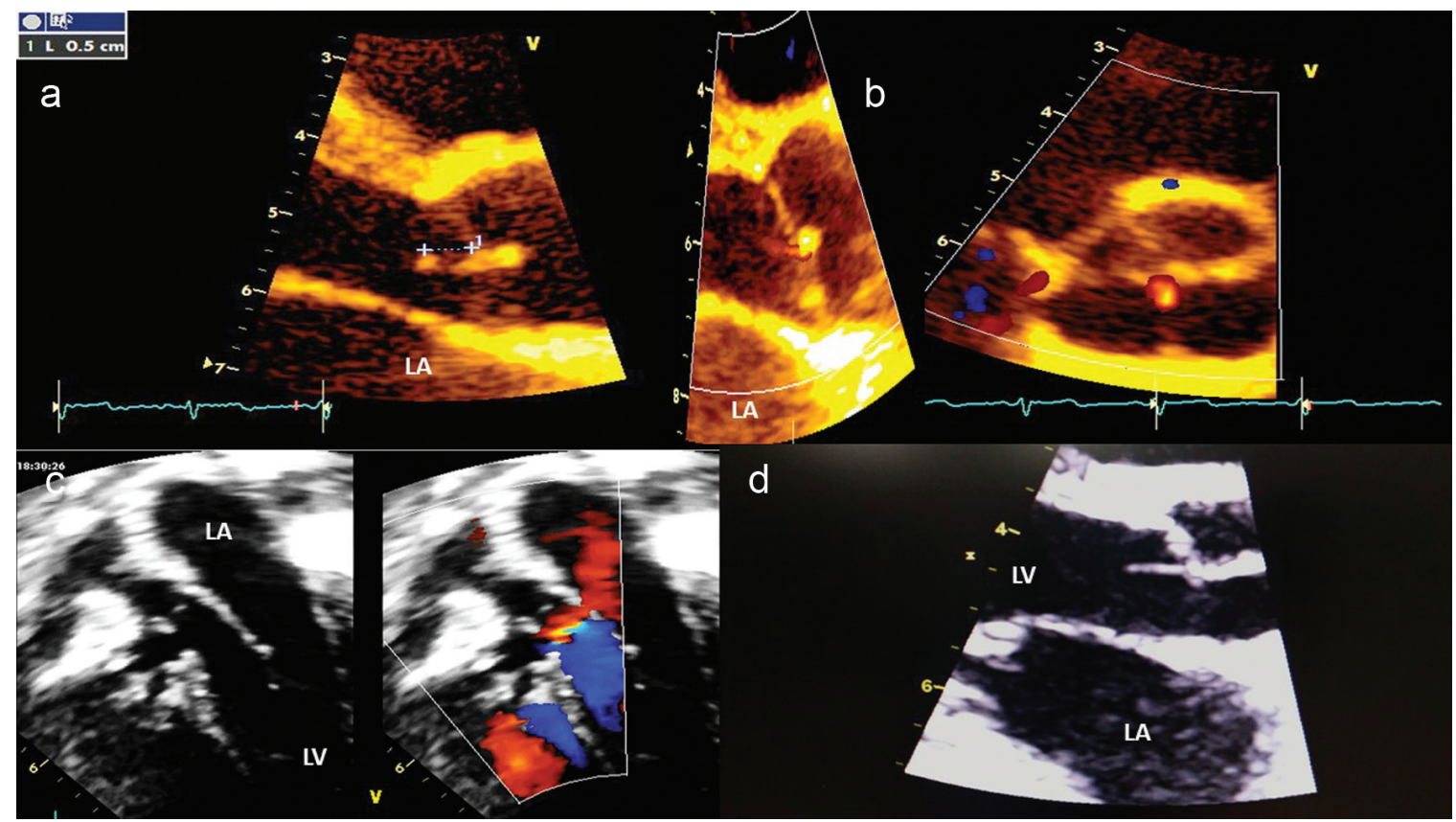

Fig. 1. Cases of LEx. (a-b) A 14 year-old male; long axis view of the aortic valve, with zoom (the LEx measured $5 \mathrm{~mm}$ ) and short and long axis views of the aortic valve with minimal aortic valve regurgitation. (c) A 4 year-old female with VSD. Apical four chamber view (LEx in the aortic valve and comparative color) and showing minimal aortic valve regurgitation. (d) A 9 year-old male with a history of Kawasaki disease; LEx in the aortic valve. Abbreviations: LEx, Lambl's excrescences; VSD, ventricular septal defect.

machine (GE Healthcare, Chicago, IL, USA). Differential diagnoses were ruled out, including laminar thrombi, endocarditis, and papillary fibroelastomas, among others.

\section{Results}

It is possible that the greater spatial and temporal resolution of the diagnostic equipment used, the transducer frequency, the use of windows with echocardiographic zoom, the experience of the examiner, and having exams focused on the left ventricular outflow tract, allowed for the incidental diagnosis of LEx (Fig. 1). Of the 17 cases presented, $64.7 \%$ were under 18 years of age. In $94 \%$ of the cases, the LEx were located on the AV; only one was on the biological mitral valve (MV). Forty-seven percent ( 8 cases) had CHDs [2: ventricular septal defect (VSD); 1: tetralogy of Fallot; 2: bicuspid AV; 1: MV repair with biologic prosthesis; 1: tricuspid atresia and Fontan circulation; and 1: aortic coarctation).

There was no direct relationship between the reason for the study and the finding of LEx in any of the pediatric cases; it was a $100 \%$ incidental finding. In fact, in two cases of syncope evaluation, the finding of LEx was not expected, given its very low frequency in the pediatric population. In two of the pediatric cases, innocent murmurs were correlated with minimal AV regurgitation, and when the exam was focused on this structure, LEx was diagnosed. In only one adult case was the exam directed towards finding the cause of syncope in the AV, but this diagnosis was not expected and neither was it the direct cause of syncope. Cases of LEx associated with CHDs were found very close to the VSD and left ventricular outflow tract. Perhaps the reason for this is that with proximity to the VSD, hemodynamic shunt forces cause stress and damage to the surface of the aortic vellums and the development of LEx. Or, perhaps, LEx can be considered to also be a congenital defect which accompanies these CHDs (Fig. 2).

Treatment was conservative in most cases; seven individuals received aspirin as preventive treatment (4: children; and 3: adults). The pediatric patients were medicated with aspirin due to their CHD. The adults were medicated with aspirin alone or in combination with atorvastatin, according to their risk factors. There was no ictus in either group on follow-up. In patients who underwent corrective surgery (CHD, valvular disease), there were no surgical reports of LEx resection (Table 1).

\section{Discussion}

In 1856, Lambl first described small filiform processes on the ventricular surface of normal and abnormal AVs. In subsequent pathologic series of normal valves, a $70 \%$ to $90 \%$ prevalence of LEx was reported, predominantly on the MV ( $70 \%$ to $85 \%$ ), followed by the AV (62\% to $90 \%)$ and the right-sided valves ( $8 \%$ to $20 \%) .{ }^{9}$ Recently, Osorio et al..$^{10}$ analyzed 33 cases of LEx, and reported the affected valve was AV in 75\% (25/33), followed by MV in $17 \%$ $(6 / 33)$ and pulmonary valve in $2.8 \%(1 / 33)$. Salah et al. ${ }^{11}$ analyzed the cases published from 1981 to 2018; in that series, the affected valve was $\mathrm{AV}$ in $89 \%$ and $\mathrm{MV}$ in $7 \%$, with one case in the pulmonary valve. Our series' results are similar and congruent with those reported, with a high incidence on the AV.

The etiology of LEx is uncertain; the constant bending and buckling of leaflets can cause tearing of subendocardial collagen and elastic fibers, with subsequent formation of a small thrombus, fibrin deposit, inflammation and fibrosis. Matsukuma et al., ${ }^{12}$ reviewed autopsy files and retrieved a total of 126 cases of AVs without infectious endocarditis. Of these, $73 \mathrm{AVs}$ were selected from patients without $\mathrm{AV}$ dysfunction and the remaining 53 were retrieved from patients with $\mathrm{AV}$ dysfunction, including aortic ste- 


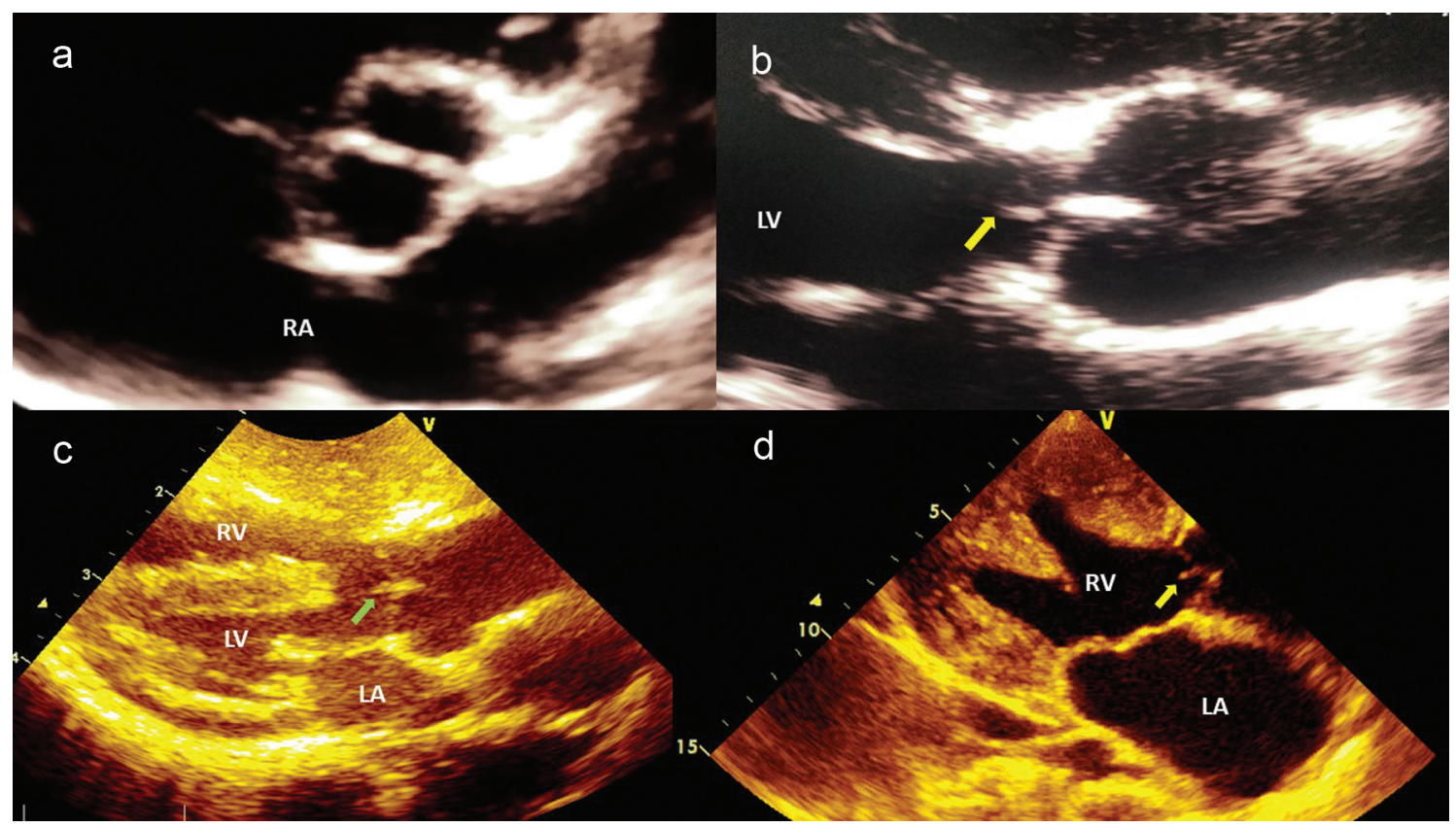

Fig. 2. Cases of LEx. (a-b) A 15 year-old male; short axis view of the bicuspid aortic valve (a) and long axis view focusing on the outflow tract and aortic valve, with zoom. The yellow arrow shows LEx. (c) A 1 month-old newborn with tetralogy of Fallot; long axis view.Green arrow shows LEx in aortic valve. (d) A 26 year-old female with double outlet right ventricle. The yellow arrow shows LEx in aortic valve. Abbreviations: LEx, Lambl's excrescences; LA, left atrium; LV, left ventricle; RA, right atrium; RV, right ventricle.

nosis and aortic regurgitation. The results showed LEx [classical and/or non-ex LEx in $106(84 \%)$ ]. Out of these, 88 (70\%) had features of classical LEx, $78(62 \%)$ had features of non-ex LEx and 60 $\mathrm{AVs}(48 \%)$ had features consistent with both classical and non-ex LEx. In the present study, the incidence of LEx was calculated to be $84 \%$, which is consistent with the previous studies. This study also further highlighted that non-ex LEx, which has previously received little attention, is more common than expected, especially in markedly deformed AVs. AV dysfunction does not seem to influence the development of LEx but the morphological changes associated with AV dysfunction can foster non-ex LEx. ${ }^{12}$

In the adult, the embolic risk of valvular LEx was evaluated by Roldan et al..$^{13}$ in a prospective study published in 2015; this study involved 90 healthy subjects and 88 patients with or without suspected cardioembolism and followed the cases clinically for approximately 4 years. The prevalence of LEx in healthy subjects $(38 \%)$ and in patients with (47\%) or without $(41 \%)$ suspected cardioembolism was similar, irrespective of age or sex, and the presence of LEx did not appear to be associated with future embolic events. These findings suggested that there may not be a direct causal link between ischemic stroke and the presence of the valve strands. ${ }^{13}$

A review of the current literature shows many different views on the clinical importance, pathophysiology, association with ischemic events and management of LEx. However, there is a general consensus amongst most of the authors that LEx should be considered in the differential diagnosis of patients who present with signs of cardioembolism, until conclusive evidence suggests otherwise. The experts recommend performing a TEE on these patients and treating them with dual antiplatelet therapy if LEx is found to be present. However, no definitive guidelines currently direct the management of LEx, and management is largely based upon case reports in the literature.

Most authors agree that the choice between surgical interven- tion versus conservative observation, including anticoagulation or antiplatelet therapy, needs to be decided on a case-by-case basis and should be based on the patient's pre-operative risk stratification. ${ }^{14,15}$ Some experts recommend close follow-up with serial echocardiograms every 6 to 12 months for asymptomatic patients with LEx; children can also be included in this group. For patients with LEx who have experienced a stroke with no alternative source of emboli, treatment with anticoagulation (warfarin therapy) or antiplatelet therapy (aspirin, 81 - $200 \mathrm{mg}$ per day, clopidrogrel $75 \mathrm{mg}$ per day) has been suggested and reported in several cases. In other reports, dabigatran or rivaroxaban has been administered. ${ }^{16,17} \mathrm{Fi}$ nally, in patients with LEx who experience recurrent strokes while on anticoagulation, a surgical debridement of the LEx can be considered.

Chu et al. ${ }^{18}$ analyzed 20 LEx cases. Nine were referred for surgical resection, with the following indications: primary or recurrent ischemic stroke, angina, weakness and fatigue, headache, mitral localization in papillary muscle and chordae tendineae, and incidental finding. In the cases analyzed by Osorio et al., ${ }^{10}$ the 2 month to 3 year follow-up period did not show any cases of recurrence of LEx or stroke (only one stroke case was reported, but it was not related to LEx). However, there is as yet no clear guide in CHD, because LEx are infrequent and there are not enough cases currently reported. Our impartial and critical opinion is to perform surgical resection at the same time as the CHD is repaired. Conservative management was the treatment of choice in 14/17 of the cases in our series; surgery was performed in only three cases, but for other reasons. However, the following hypothesis arise: 1. Can LEx be an isolated congenital defect? 2. Do LEx occur in association with CHD?

The low prevalence of LEx in the general population, and even more so in the pediatric population, gives rise to the following questions: What is the importance of knowing the diagnosis in childhood, given that relationship with cryptogenic ictus in adult- 
hood is known? Is it important to routinely look for LEx if they are asymptomatic in pediatric patients and become less visible as the children grow (lower echocardiographic resolution due to a difficult acoustic window)? The best recommendation is to report these findings in the echocardiographic studies performed and follow-up during childhood, adolescence and adulthood, evaluating the risk factors and following the recommendations of the experts to initiate anticoagulation or antiplatelet therapy.

The importance of this case series report is the coincidence with CHD; there are no known descriptive case series in adults or children. This report also raises questions such as: What would be the best course of action when LEx are found? Should they be resected during CHD surgical repair? The real dilemma lies in that, due to their low frequency, they are not routinely looked for, CHD repair focuses only on the cardiac defect, and LEx may remain as a persistent residual following CHD repair.

\section{Conclusions}

This case series leads us to think that LEx cases are really much more prevalent than currently reported in the literature. Furthermore, they are associated with CHD and may be of some importance in the cause of CHD-associated stroke. Many times, patients with unrepaired and repaired CHD have an embolic stroke as a result of CHD residuals (e.g., residual VSD following atrioventricular canal repair). The fact that LEx and CHD are an association that heightens the risk of stroke in this population arouses our research interest.

These case descriptions motivate the search for LEx related to $\mathrm{CHD}$, and pose the question of whether their origin is also congenital or rather a direct consequence of the classic description of natural valvular wear and tear, increased by the hemodynamic effects of CHD. At present, there are no large series or controlled studies which can answer these questions. However, this contribution of cases will undoubtedly awaken the interest of more expert investigators.

\section{Acknowledgments}

There was no private or public sector funding for this research.

\section{Conflict of interest}

The authors have no conflict of interests related to this publication.

\section{Author contributions}

John Jairo Araujo: collected the data, performed echocardiograms, wrote the paper; Tareq Rahimy: collected the data, wrote the paper.

\section{References}

[1] Lambl VD. Papillare exkreszenzen an der semilunar-klappe der aorta. Wien Med Wochenschr 1856;6:244-247.

[2] Aziz F, Baciewicz FA Jr. Lambl's excrescences: review and recommendations. Tex Heart Inst J 2007;34(3):366-368.

[3] Kamran H, Patel N, Singh G, Pasricha V, Salifu M, McFarlane SI. Lambl's excrescences: A case report and review of the literature. Clin Case Rep Rev 2016;2(7):486-488. doi:10.15761/ccrr.1000254.

[4] Phillips A, Qureshi M, Eidem B, Cetta F. Lambl's excrescences in children: Improved detection via transthoracic echocardiography. Congenit Heart Dis 2018;13(2):251-253. doi:10.1111/chd.12560.

[5] Yacoub H, Walsh A, Pineda C. Cardioembolic stroke secondary to lambl's excrescence on the aortic valve: a case report. J Vasc Interv Neurol 2014;7(3):23-25.

[6] Pizzuti A, Parisi F, Mosso L, Cali' Quaglia F, Tomasello A. Acute myocardial infarction in a patient with two-vessel oclusion and a large lambl's excrescence. Case Rep Cardiol 2016:8370212. doi:10.1155/2016/8370212.

[7] Ozturk C, Haqmal H, Balta S, Demirkol S, Unlu M, Koklu M, et al. The association of severe aortic stenosis and narrow aortic root in a young patient-What is the etiology: Rheumatic valvulitis or lambl's excrescences? Int J Cardiol 2016;208:87-91. doi:10.1016/j. ijcard.2016.01.018.

[8] Sun J, Ahser C, Yang X, Cheng G, Scalia G, Massed A, et al. Clinical and echocardiographic characteristics of papillary fibroelastomas: a retrospective and prospective study in 162 patients. Circulation 2001;103(22):2687-2693. doi:10.1161/01.cir.103.22.2687.

[9] Roldan C, Shively B, Crawford M. Valve excrescences: prevalence, evolution and risk for cardioembolism. J Am Coll Cardiol 1997;30:13081314. doi:10.1016/s0735-1097(97)00315-x.

[10] Osorio B, Hou L, Xu J, Pagan E, Piscopiello M. Lambl's excrescences and a review of therapeutic strategies. Case Reports in Internal Medicine 2018;5(3):13-17. doi:10.5430/crim.v5n3p13.

[11] Salah H, Majdalany D, Conway D. Lambl's excrescences - taking the crypto out of cryptogenic stroke: a case report and literature review. Am J Med Case Rep 2018;6(10):214-217. doi:10.12691/ajmcr-6-10-5.

[12] Matsukuma S, Koga A, Takeo H, Kato K, Mori K, Sato K. Non-exophytic Lambl excrescences of aortic valves: a morphological study. Histopathology 2016;69(2):307-314. doi:10.1111/his.12938.

[13] Roldan C, Schevchuck O, Tolstrup K, Roldan P, Macias L, Qualls $C$, et al. Lambl's excrescences: association with cerebrovascular disease and pathogenesis. Cerebrovasc Dis 2015;40(0):18-27. doi:10.1159/000381906.

[14] Kalavakunta JK, Peddi P, Bantu V, Tokala H, Kodenchery M. Lambl's excrescences: a rare cause of stroke. J Heart Valve Dis 2010;19(5):669670.

[15] Davogustto G, Fernando RR, Loghin C. Lambl's excrescence, migrainous headaches, and "tiger stripes": puzzling findings in one patient. Tex Heart Inst J 2015;42:70-72. doi:10.14503/thij-13-3808.

[16] Jo K, Kim J, Jang W, Lee M. Lambl's excrescences associated with cyptogenic stroke. J Neurol Sci 2017;381:525. doi:10.1016/j. jns.2017.08.3688.

[17] Meireles V, Santos V, Barbosa R, Pereira A, Conde A. Lambl's excrescences in a woman with recurrent changes of consciousness. Rev Med Saude Brasilia 2017;6(1):45-53.

[18] Chu A, Aung TT, Sahalon H, Choksi V, Feiz H. Lambl's excrescence associated with cryptogenic stroke: a case report and literature review. Am J Case Rep 2015;16:876-881. doi:10.12659/ajcr.895456. 